\title{
Commentary on "Predictors of postoperative complications from stress urinary incontinence procedures: a NSQIP database study"
}

\author{
Marianne Koch ${ }^{1}$ (D)
}

Received: 1 December 2021 / Accepted: 6 December 2021 / Published online: 3 January 2022

(c) The International Urogynecological Association 2021

Midurethral sling surgery is the most common surgical treatment for stress urinary incontinence. This study was aimed at identifying risk factors for postoperative complications after midurethral sling surgery using the American College of Surgeons National Surgical Quality Improvement Program database.

Patient charts of 16,491 women who had received midurethral sling surgery between 2014 and 2018 were included. Outcome parameters were postoperative complications within 30 days of surgery and readmission and reoperation rates. Postoperative complications occurred in $4.2 \%$ of patients, of which urinary tract infection was the most frequent $(3.4 \%)$. Older age ( $\geq 80$ years), ASA (American Society of Anesthesiologists) class III and IV, and belonging to minority races were associated with increased odds of complications and readmissions. Overall, 30-day readmission rates and reoperation rates were low $(1.5 \%$ and $1 \%$ respectively).

Results from this large database confirm that midurethral sling surgery is a safe procedure, with low and mostly nonsevere complication rates, even in older patients.

\section{Declarations}

Conflicts of interest None.

Publisher's note Springer Nature remains neutral with regard to jurisdictional claims in published maps and institutional affiliations.
Marianne Koch

marianne.koch@meduniwien.ac.at

1 Department of Obstetrics and Gynecology, Medical University of Vienna, Spitalgasse 23, 1090 Vienna, Austria 